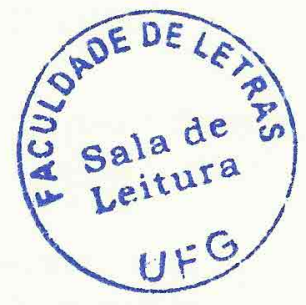

Artigos 


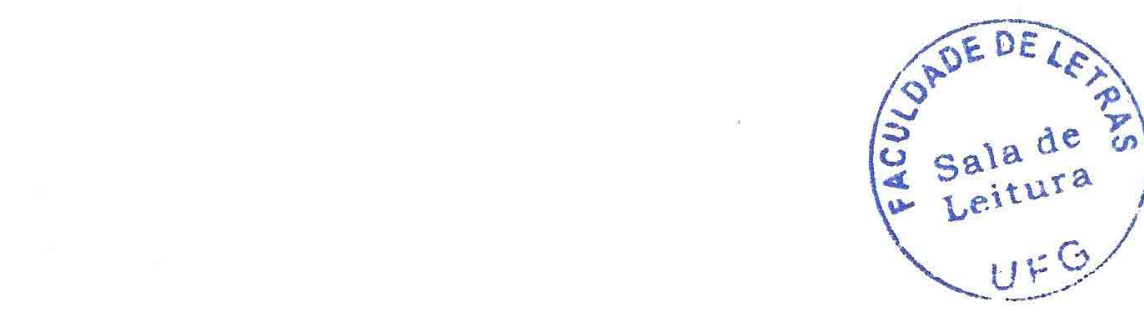

\title{
O FANTASMA DO AUTORITARISMO NAS NARRATIVAS DE VICTOR GIUDICE
}

André Scoville*

\begin{abstract}
RESUMO: Percorrendo a trajetória literária do escritor Victor Giudice, nota-se em suas narrativas uma preocupação recorrente com a questão do autoritarismo. A publicação de suas obras coincide com momentos-chave da história politica brasileira. Utilizando uma linguagem metafórica, Giudice aborda as transformações políticas que transcorrem no período que vai do auge da violência institucionalizada pela ditadura militar até a fase de consolidação do regime democrático. Suas narrativas também suscitam a reflexão sobre o autoritarismo como elemento presente nas relações sociais.
\end{abstract}

PALAVRAS-CHAVE: Victor Giudice; literatura brasileira contemporânea; política; autoritarismo; ditadura militar.

$\mathrm{O}$ que têm em comum os anos de 1972, 1979, 1985, 1989, 1994, 1995? História política brasileira? Pode ser. Auge da ditadura militar, abertura e lei da anistia, eleição indireta e morte de Tancredo Neves, primeira eleição direta para presidente, segunda eleição direta e início do período FHC. Faz sentido, mas não é bem disso que eu quero tratar. Ou é? Afinal, coincidentemente, estes são também os anos das primeiras edições dos livros de Victor Giudice. Quer dizer, a obra de Giudice, um escritor lamentavelmente já meio esquecido até mesmo no meio acadêmico,

- Doutorando do Programa de Pós-Graduação em Letras da Universidade Federal do Paraná - UFP. 
atravessa esse período que vai da ditadura à democracia, passando pela interminável (quem viveu, sabe...) transição política.

Irônico, debochado mesmo, Giudice - falecido em 1997 - era um escritor que por meio do insólito ficcional denunciava o insólito do real. Foi pelo viés metafórico que Giudice fez sua crítica ao autoritarismo tanto da macropolítica nacional quanto da micropolítica (esta, sim, seu alvo prioritário) das relações sociais. Seu conto mais conhecido, "O arquivo", que abre Necrológio (1972), primeiro livro de Giudice, já aborda essa relação macro-micro na configuração do personagem joão (com inicial minúscula mesmo) como alguém destituído de qualquer relacionamento afetivo com outras pessoas e feliz com os sucessivos rebaixamentos de cargos e reduções de salários que recebe como recompensa por sua dedicação à empresa em que trabalha. A história particular de joão, que termina com sua transformação num arquivo de metal, remete, por certo, ao âmbito mais amplo de um processo progressivo de perda de poder econômico e piora da condição de vida dos trabalhadores assalariados. Em 1972, o Brasil vivia o período do "milagre econômico" e divulgava-se a ilusão de que o crescimento da economia traria benefícios diretos para a população mais carente. Ao invés disso, o milagre teve como grave conseqüência o incremento do processo de concentração de renda e de desigualdade socioeconômica que ainda hoje aflige o país.

Mas esse paralelo ainda era muito sutil para ser percebido pelos censores da ditadura. O conto "O arquivo" foi publicado sem maiores problemas, entretanto o mesmo não ocorreu com "O hotel", que a censura proibiu naquele mesmo ano de 1972. Esse conto ficou guardado por 22 anos e acabou sendo publicado somente em 1994, quando a pequena editora Leviatã, lançou O Museu Darbote outros mistérios, último livro de contos de Giudice. Com isso, meio pelo acaso, foram unidas duas pontas soltas da nossa história ao 
Rev. ANPOLL, n' 21, p. 11-27, jul./dez. 2006.

serem colocados num mesmo volume dois contos que tratam de dois hotéis em dois momentos históricos distintos.

O Hotel da Morte, que aparece no conto "A história que meu pai não contou”, é este segundo hotel que, de certo modo, vem contrastar com aquele de 1972. Ambos os hotéis são exemplos de um procedimento que Giudice utilizou de modo recorrente em suas narrativas: a troca de função de determinado espaço. No caso, os hotéis são transformados em prisões. Metaforicamente, esses espaços são também zonas de transição entre vida e morte. No entanto, por trás das semelhanças entre os dois contos, está uma diferença que diz respeito exatamente à mudança politica ocorrida no intervalo de escrita entre um e outro. Sobre "O hotel", voltarei a falar mais adiante. É melhor fazer o caminho inverso, começando pelo conto mais recente.

Em "A história que meu pai não contou", as pessoas que não desejam mais viver, mas não conseguem cometer suicídio, procuram o Hotel da Morte que se incumbe da tarefa. Ao se registrarem nesse hotel, os hóspedes tomam conhecimento dos regulamentos e assinam um termo de responsabilidade que os impede de desistir do acordo e de abandonar o hotel. Ficam isolados do mundo exterior aguardando a morte, que não sabem nem como nem quando vai acontecer.

O Hotel da Morte é um espaço imaginado/sonhado pelo personagem Victor Giudice, com 11 anos de idade, a partir de uma história contada pelo pai. A narrativa se desenvolve num entrelace de sonho e realidade (dentro do universo ficcional), assim como de ficção e elementos da biografia do escritor Giudice que são incorporados. Ali se misturam presente, passado e futuro num espaço criado pela memória e pela imaginação.

O conto é narrado por um Victor Giudice presumivelmente adulto que relembra como o impressionou a história do Hotel da Morte que o pai contou ao menino Victor. Ele recorda como essa história leva o menino Victor, com 11 anos de idade, a imaginar 
uma outra história, a história que o pai não contou, em que o protagonista é Victor Giudice aos 21 anos. As interseções e sobreposições prosseguem ao se descobrir que o imaginário Victor de 21 anos se registra no Hotel da Morte devido a uma desilusão amorosa ocorrida aos seus 11 anos, quando sentia que sua paixão pela colega de classe, Sara Maria, não era e nunca seria correspondida.

O reencontro do personagem com Sara Maria, também hospedada no hotel, desperta em ambos a vontade de quebrarem o acordo firmado e fugirem daquele local. Antes do reencontro, o hotel era visto por Victor como um lugar agradabilíssimo. A primeira noite de sono é descrita como uma das mais esplendorosas de sua vida. Um dos hóspedes era um excelente pianista que lhe proporcionava performances maravilhosas em pianos das melhores marcas. A comida era deliciosa, e o hotel localizava-se numa área extensa como um "parque resplendente de vida" repleto de "canteiros floridos, árvores centenárias, caminhos românticos, pássaros cantores e hóspedes silenciosos." (GIUDICE, 1999: 80-81) Nesse espaço, composto paulatinamente, cada elemento é cuidadosamente escolhido pelo menino Victor. As eventuais lacunas são preenchidas pela imaginação do menino que demonstra controlar a construção do espaço imaginado, como se nota nesse trecho: “Quando o funcionário me pediu a bagagem, eu levei um susto, uma vez que não havia pensado nisso. Mas, como sempre, a imaginação encontrou o melhor caminho: com suprema naturalidade, apontei o Ford de meu pai."(GIUDICE, 1999: 79-80)

No entanto, em certo momento, a imaginação do menino começa a ser representada como se ganhasse autonomia, não podendo mais ser controlada, deixando subjacentes as idéias de que alguém se deixa levar pela imaginação ou ainda de que personagens e eventos possam ser também dotados de vontade própria. Essa perda de controle sobre a história também pode refletir o momento (ainda que este não esteja marcado no texto) em que o menino adormece, expressando uma passagem da invenção consciente à onírica. 
Rev. ANPOLL, n' $\mathrm{n}^{0}$ 1, p. 11-27, jul./dez. 2006.

O reencontro com Sara Maria ocorre já nessas circunstâncias e faz com que o espaço se torne opressor. Os demais hóspedes passam a ser vistos como sentinelas. O pianista desaparece e o piano se fecha. Victor percebe somente então que o hotel é "cercado por muros altíssimos, com a parte superior recheada de cacos de garrafas"(GIUDICE, 1999: 86); e para completar a mudança de perspectiva, no momento combinado para a tentativa de fuga, cai sobre o hotel uma incrivel tempestade, repleta de trovões e relâmpagos.

Muitos elementos transitam entre os diferentes espaços e tempos que compõem a narrativa e alguns deles chegam a extrapolála na direção de possiveis referências à própria biografia do autor. É o caso do Ford cupê, verde escuro, pertencente ao pai, citado no inicio e no fim desse conto, que também é mencionado no conto "A única vez", do mesmo livro, e que remete a um carro do pai do autor. ${ }^{1}$

O que se percebe nesse conto é, como já mencionado, um espaço recebendo as funções de outro, ou seja, tem-se aí um hotelprisão. O Hotel da Morte é, segundo seus estatutos, efetivamente uma prisão e o personagem Victor torna-se um condenado à morte no instante em que toma conhecimento dos termos e assina seu registro. Victor, no entanto, apenas o percebe como prisāo a partir do momento que não deseja mais permanecer lá dentro, no momento em que quer romper o contrato estabelecido.

O outro hotel-prisão de Giudice é aquele que aparece no conto "O hotel". As semelhanças entre esses dois hotéis são menos relevantes que suas diferenças. A começar pelo fato que, em "O hotel", o casal protagonista não sabe que o hotel que escolhem para passar a lua-de-mel é também uma "prisão". Não há um regulamento explicitando isso, e o casal demora a reconhecer os sinais de que sua liberdade está ameaçada. O processo começa com a supressão de regalias e de certos confortos prometidos a preços irrisórios na

1 Uma fotografia com familiares de Victor ao redor desse carro está disponibilizada no endereço eletrônico http://members.nbci.com/v_giudice. 
propaganda que os atraiu até o hotel. As comodidades vão sendo restringidas e eliminadas uma após a outra, sempre acompanhadas por explicações e desculpas dos funcionários, até se instituir o impedimento de deixar o hotel.

O esforço de adaptabilidade que o casal demonstra às novas condições restritivas vai ser abandonado tarde demais. Quando afinal percebem a gravidade da situação, o marido decide por um enfrentamento que acarreta sua morte. Em "O hotel", Giudice lida exatamente com as mesmas condições de sobrevivência que regulam o modo de vida dos habitantes de Harmonisópolis, do conto "Os pontos de Harmonisópolis", que faz parte do livro Necrológio. Percebe-se, em ambos os contos, a influência do contexto político da década de 1970. O conto "Os pontos de Harmonisópolis" remete metaforicamente a qualquer regime autoritário, mas também àquele determinado periodo da ditadura militar no Brasil. A cidade Harmonisópolis é um lugar onde as pessoas são admitidas como residentes mediante a permissão de um Comando. Nesse lugar, as pessoas rejuvenescem graças aos "ares profiláticos" da cidade. Ali todas as instituições foram abolidas, com exceção de uma instituição particular, a morte. Todos os medos também foram eliminados, com exceção de um, o medo dos "pontos”, responsáveis pela eliminação de pessoas que, mesmo inconscientemente, não desejam mais viver e daquelas que passam a questionar a autoridade do Comando. Ou seja, Harmonisópolis é o "lugar perfeito", desde que a pessoa que ali habita siga essas duas regras: manter sempre sua vontade de viver e nunca pensar em contrariar o Comando.

É evidente a relação que se pode estabelecer com o momento político que o país atravessava. Além disso, o próprio nome Harmonisópolis pode ser visto como uma ironia de Giudice para com a "Cidade Maravilhosa". Nesse sentido, os ares profiláticos, o cuidado extremo com a limpeza urbana, os ônibus inodoros e o silêncio de Harmonisópolis também são críticas irônicas ao caos ambiental de grandes metrópoles como o Rio de Janeiro. Essas crí- 
Rev. ANPOLL, no 21, p. 11-27, jul./dez. 2006.

ticas que aludem à situação política do Brasil na década de 70 não foram percebidas pela censura.

A questão da adaptabilidade dos personagens à violência institucionalizada a que estão submetidos pode ser notada em vários contos de Giudice. Em "O arquivo", o personagem joão já está adaptado às condições estabelecidas pela empresa e as aceita com naturalidade, mesmo porque não conhece outras. Em "Os pontos de Harmonisópolis", há uma troca consciente (as regras também são conhecidas - se não desde o princípio, ao menos no decorrer da narrativa) da liberdade pessoal pela vantagens de se viver naquele lugar especial: o protagonista pretende se adaptar. De modo semelhante, o personagem Victor, em "A história que meu pai não contou", conhece as regras e voluntariamente se sujeita a essas regras que correspondem, neste caso, exatamente à sua vontade. Quando muda de idéia, ele decide contrariá-las e romper o acordo. Em "O hotel”, as condições não estão previamente esclarecidas para o casal e vão sendo estabelecidas e percebidas como um processo, como uma armadilha que se revela aos poucos. O casal segue se adaptando e aceitando as restrições até que se atinge um limite. Quando o marido de "O hotel" revolta-se contra a situação e decide passar para a ação, tem um fim trágico.

Como se vê, tem-se nos contos de Giudice todo um espectro de graus de adaptabilidade dos personagens que vai da passividade absoluta até a ação efetiva e contestadora. As variáveis envolvidas são a relação de conhecimento ou desconhecimento prévio das regras impostas e o conflito entre a vontade de libertação e a submissão, muitas vezes adotada como estratégia de sobrevivência. Nesse sentido, o personagem Victor, de "A história que meu pai não contou”, ocupa um dos extremos do espectro, uma vez que não apenas tem conhecimento das regras, como estabelece um contrato atestando seu conhecimento. Ainda assim, decide ignorá-las. Além disso, a submissão aos termos do contrato, nesse caso, não garantiria sua sobrevivência, mas levaria inevitavelmente à sua morte. Por- 
Scoville, André. O fantasma do autoritarismo nas narrativas de Victor Giudice

tanto, ao recuperar sua vontade de viver, o rompimento do acordo é sua única alternativa. Infere-se, a partir dessa perspectiva, que nem tudo pode ser objeto de contrato.

Em "O hotel", não há o contrato, o que há é um exercício do poder autoritário. As regras são unilaterais e as imposições são apresentadas conforme a vontade de quem detém esse poder, mas sempre através de seus intermediários, empregados que demonstram seu próprio constrangimento e sua condição de simples seguidores de ordens. A adaptação às restrições não é uma opção para os personagens, mas uma obrigação, sendo que as conseqüências de uma confrontação sequer estão esclarecidas.

Nesse conto, a transformação do hotel em prisão está relacionada com a mudança de gerente. O novo gerente é o centro do poder e fonte de todas as proibições e, como em O castelo, de Kafka, é um poder invisivel, inatingivel e inquestionável. Suas sucessivas proibições refletem, portanto, a instauração e o enrijecimento de um regime autoritário. Os hóspedes perdem algumas comodidades e vão tendo suas opções restringidas até o momento em que não podem mais optar, têm que aceitar o que lhes é oferecido. É o que acontece, por exemplo, com suas refeições. Tratando-se das restrições ao espaço que podem freqüentar, percebe-se em andamento, desde sua chegada ao hotel, o processo de encarceramento. A praia particular do hotel, cercada por muros altos, é vista inicialmente como um privilégio para os hóspedes, mas a redução progressiva da faixa de areia que pode ser ocupada aponta as primeiras etapas desse processo que culmina na proibição de sair do quarto. Verifica-se, portanto, uma relação estreita entre espaço e liberdade que remete ao contexto político. Numa comparação entre os hotéis de "A história que meu pai não contou" e de "O hotel", percebese que vigora no primeiro o regime de direito e no segundo o de exceção.

Outra manifestação de poder autoritário aparece no conto "Jurisprudência”, de O Museu Darbot e outros mistérios. em que é narra- 
Rev. ANPOLL, no 21, p. 11-27, jul./dez. 2006.

da a prisão arbitrária de um operário, Cipião, ao retornar para casa após seu primeiro dia de trabalho. O título do conto remete com ironia ao termo jurídico tanto pela sua definição como o conjunto de princípios de direito ou ainda de decisões judiciais conexas e coerentes, como pela própria prudência que integra o termo. A evidente relação com o tema de O processo, de Kafka, pode também ser vista no título desse conto, tanto como insinuação de uma jurisprudência estabelecida nos casos de Joseph K. e de Cipião, como em sentido metafórico, numa possibilidade de diálogo do escritor Giudice com o escritor Kafka, numa espécie de "jurisprudência literária".

Giudice situa o conto no Rio de Janeiro, trazendo, assim, o tema para o contexto brasileiro em que prisões arbitrárias e justiça morosa não parecem tão insólitas quanto deveriam parecer, principalmente considerando que a prisão de Cipião ocorre num período de regime ditatorial.

Mesmo com a vigência de uma ditadura, Cipião tem certeza que tudo não passa de um engano e que sua liberdade será restituida rapidamente. Como Joseph K., Cipião acredita na justiça. No entanto, o personagem de Kafka desconhece plenamente a acusação e a certeza de sua inocência é muitas vezes minada por um sentimento de culpa. Já Cipião tem elementos mais concretos com os quais pode responder (ao menos para si) essa questão de ser inocente ou culpado. Não se esclarece do que é acusado, mas sua confrontação com as supostas vítimas permite a Cipião manter-se convicto de sua inocência, mesmo porque "alimentava a mais saudável certeza de nunca ter escorregado um milímetro fora da lei."(GIUDICE, 1999: 65)

Como o transcurso dos anos, Cipião vai afinal perdendo a esperança de ter sua liberdade devolvida. Sem tribunais e ritos judiciais, não há julgamento, portanto não há defesa, e a decisão sobre o caso parece depender apenas da polícia, tomada aqui como expressão da justiça - não apenas agente, mas também juiz. A intervenção de outra esfera de poder, por meio do homem misterioso 
Scoville, André. O fantasma do autoritarismo nas narrativas de Victor Giudice

("chefe do departamento de não sei o que ministerial, e mais não sei o que judiciário" - GIUDICE, 1999: 76) vai ocorrer apenas após 50 anos de prisão, quando (mais uma vez diferentemente de $O$ processo) o engano é, por fim, reconhecido.

Em 14 de fevereiro de $1990^{2}$, Cipião é libertado. A ironia de uma justiça que tarda, mas não falha, é complementada com a compensação escolhida para a remissão do erro. Cipião recebe de presente um Colt calibre 38 e "o direito a cometer dois homicídios de qualquer espécie, ou outros delitos cuja pena estivesse circunscrita a cinqüenta anos, sem ser submetido a julgamento ou a algum tipo de pressão legal."(GIUDICE, 1999: 76) Justiça que tarda, liberdade ainda que tardia. Cipião está livre, assim como aqueles que o prenderam. Observa-se novamente uma relação com o período de autoritarismo e com o retorno à liberdade, devolvida sob a condição de que o passado seja esquecido para que a democracia possa seguir seu curso.

A reparação oferecida pelo Estado à Cipião segue a lógica da justiça ao estipular a pena, em que para cada delito corresponde uma quantidade de tempo de reclusão. Como Foucault observa, em Vigiar e punir, não faz tanto tempo assim que essa relação quantificada entre delito e punição se tornou a lógica da justiça: "A prisão é 'natural' como é 'natural' na nossa sociedade o uso do tempo para medir as trocas."(FOUCALT, 1977: 208) O desfecho de "Jurisprudência", assumindo a possibilidade de inversão da ordem dos acontecimentos (punição e crime, ao invés de crime e punição) simplesmente se apóia na mesma lógica. Entretanto, essa inversão é o clímax do absurdo que orienta todo o caso da prisão de Cipião.

A conotação política da prisão arbitrária, aludida nesse conto, já aparece explicitamente no romance Bolero. Escrito ao longo de sete anos, de 1979 a 1985, esse romance é publicado quando o país comemorava ainda meio desconfiado o advento da Nova República e

2 A data da prisão e da libertação (14 de fevereiro) coincide com a data do aniversário do pai de Cipião e também, vale lembrar, do próprio Victor Giudice. 
Rev. ANPOLL, $n^{\circ} 21$, p. 11-27, jul./dez. 2006.

o fim da seqüência de governos militares que se iniciara no já longínquo ano de 1964. Havia a consciência de que o regime autoritário tinha sido, afinal, superado, todavia as eleições diretas presidenciais não haviam ainda ocorrido, e a morte de Tancredo, que teve como conseqüência a posse do ex-arenista José Sarney, espalhava uma fumaça escura nos ares democráticos. Em Bolero, Giudice escreve uma alegoria que expõe as incertezas desse periodo de transição.

O episódio da prisão do narrador e seus desdobramentos são aspecto central de Bolero, em que o narrador passa de completo alienado em relação às transformações políticas do lugar onde vive (a instauração da monarquia na Cidade) a herói involuntário da causa republicana. Tendo passado sete anos no corredor de uma maternidade, esperando a mulher dar à luz, o narrador não acompanhou a mudança de poder, não conhece as novas leis da Cidade e, logo após desistir da espera e sair da maternidade, vai até um parque e ingenuamente colhe uma flor dourada (simbolo oficial da Monarquia), o que acarreta sua detenção pela polícia do governo monárquico. O delito é, portanto, conhecido, apesar do motivo da prisão não ser compreendido pelo narrador. Mais tarde, ao ser indagado pelo companheiro de cela se era um ladrão, um assassino vulgar ou preso político, o narrador responde: "Diante da tripla opção, confessei o que podia: - Ladrão." (GIUDICE, 1985: 34) No desenvolvimento da narrativa é que se dá a conscientização do personagem em relação ao contexto político em que vive. Na prisão, o narrador é torturado seguidas vezes, até que, depois de meses, é libertado sem receber qualquer explicação ou reparação.

Saindo da prisão, o narrador constata: "É quase impossivel que a restituição da liberdade seja um caso tão banal. Uma solidão no meio-fio, um terno velho e uma nuvem pairando sobre a cabeça dó libertado."(GIUDICE, 1985: 70) Bem mais tarde, quando já está mais a par das transformações da Cidade, o narrador será capaz de refletir: "Ao atravessar a porta da prisão e pisar a rua, estava eu 
saindo da prisão ou entrando nela?" (GIUDICE, 1985: 114) A experiência na prisão ganha novos sentidos para o narrador e acaba se confundindo com sua própria identidade, numa mitificação alimentada por outros personagens que se contrapunham ao regime autoritário. Ter sido preso e torturado passa a ser uma virtude e o narrador torna-se um herói.

Prisão pode significar pontual e separadamente tanto o edificio em si (elemento espacial), como o momento específico (elemento temporal) em que alguém é preso. Ao assumir também o sentido de punição, passa a caracterizar-se como a inevitável associação de elementos de espaço (ainda lugar em que se cumpre o castigo) e tempo (não mais o momento, mas um periodo). A prisão-punição, tomada sob a perspectiva do aprisionado, relaciona-se com a noção de uma experiência pessoal em que se incrementam as subjetividades de interpretação. Como tal, modifica-se na percepção dos dois elementos (espaço e tempo) que a compõem. Talvez por isso sejam tão freqüentes os relatos que, diante da perda de referências objetivas, deformam espaço e tempo. Há um bom exemplo disso, em "Jurisprudência", em que o narrador, com seu ponto de vista exterior, pode guiar-se pelas marcações objetivas de espaço e tempo, porém, somente por ter acesso à consciência de Cipião, consegue estabelecer a relação entre espaço e tempo objetivos e a percepção subjetiva do personagem: "[Cipião] Caminhou por uma infinidade de corredores de cem metros, que a memória dilata para quilômetros, e terminou numa cela de dois metros, que a memória reduz para centímetros." (GIUDICE, 1999: 68)

Por certo, a perda de referências espaciais e temporais não se manifesta apenas na experiência do aprisionado, mas tem ali, naquele espaço de isolamento, uma situação exemplar. O confronto dos modos objetivo e subjetivo de perceber o tempo parece mesmo ganhar intensidade em situações de isolamento. O tempo que o narrador de Bolero passa na maternidade (sete anos) só pode ser comprovado com o auxílio de algum "instrumento de medição". Mas 
Rev. ANPOLI, n ${ }^{0} 21$, p. 11-27, jul./dez. 2006.

o relógio do narrador e o do corredor da maternidade estão parados, então o tempo se dilata e o narrador se deixa levar mergulhado num contínuo que assume ares de eternidade. É necessário que a enfermeira Auriflor intervenha para que o narrador retorne ao tempo dos relógios: "O senhor sabia que hoje faz sete anos que está sentado neste banco, esperando sua mulher dar à luz? Não acredita?" (GIUDICE, 1985: 10)

Retornar ao tempo dos relógios é, para o narrador, abandonar a espera e retornar à vida. A comprovação do tempo decorrido não se dá apenas no testemunho de Auriflor, mas recebe uma inusitada materialidade na disposição de xícaras de café que cumprem ali as funções do objeto relógio.

Foi. Sete anos. Dois mil quinhentos e cinqüenta e sete dias. Sessenta e um mil trezentas e setenta e oito horas. $E$ isto é nada, desde que não haja relógios, calendários ou enfermeiras de joelhos pontudos cronometrando a vida. A revelação dos sete anos que eu nunca sentira passar fizera-me compreender os espaços entre as xicaras de porcelana distribuídas diabolicamente pela bruxa de pernas-ponteiro: o tempo infinito transformado em tempo divisivel e agora pesando em mim os sete motivos para eu me levantar e dar o fora.(GIUDICE, 1985: 10-11)

Numa reflexão posterior, o narrador afirma: "Meu reinado [rei da espera] de sete anos teria durado muito mais, caso o tempo não me fosse informado pela cronometria das xícaras de porcelana." (GIUDICE, 1985: 21)

O tempo expulsa o narrador da eternidade e o coloca de volta no mundo. Para o mundo, o relógio nunca parou, a história prosseguiu, a Cidade se transformou e o narrador sofrerá as conseqüências de não haver acompanhando essas transformações. Nesse sentido, a maternidade configura-se ainda melhor como espaço de isolamento do que a prôpria prisão, uma vez que nesta o narrador tem o seu primeiro estágio de reaproximação com o mundo, enquanto naquela promove-se o seu distanciamento. 
Como metáfora, pode-se sempre fazer a conexão entre espaços de isolamento e prisões. Prisões nem sempre parecem prisões, entretanto, é interessante observar como, mesmo quando a atenção é direcionada aos elementos espaciais em suas formas arquiteturais (características fîsicas) a relação pode ainda persistir. Foucault também destacou essa semelhança quando propôs a questão: "Devemos ainda nos admirar que a prisão se pareça com as fábricas, com as escolas, com os quartéis, com os hospitais, e todos se pareçam com as prisões?" (FOUCAULT, 1977: 199)

As semelhanças físicas estão imbricadas, como se percebe na questão levantada por Foucault, com as relações de poder identificadas naqueles espaços. Os elementos materiais e imateriais se complementam na configuração do espaço.

Em seu primeiro interrogatório oficial na prisão, o narrador de Bolero está num local que descreve imediatamente como um escritório: “A coisa tinha aspecto de um escritório, com calendários de mulheres nuas, é-proibidos, boletins, máquinas de escrever, móveis descascados, olhares, explicações, lamentos, desordens."(GIUDICE, 1985: 21) Os objetos listados ajudam a compor uma imagem do espaço físico e, ao mesmo tempo, remetem a significados que levam a uma interpretação dos mecanismos de funcionamento, dos valores, das relações de poder que vigoram naquele espaço. Naqueles objetos, lê-se a burocracia, o exercício de autoridade, a decadência e o descaso. Na lista, agregam-se ainda elementos (olhares, explicações, lamentos) que expressam a forma de relacionamento, exigida e esperada, que deve prevalecer entre aquele que detém o poder (policial, chefe,...) e aquele que responde ao poder (preso, subordinado,...). O último item (desordens) sintetiza a apreensão material e imaterial que o narrador faz daquele espaço e, simultaneamente, contrasta com a função da prisão, equipamento que auxilia a "preservação da ordem". Espaço de ordem e desordem. 
Rev. ANPOLL, $\mathrm{n}^{\circ} 21$, p. 11-27, jul./dez. 2006.

O narrador prossegue sua descrição, tendo deixado para citar ao final exatamente os elementos que mais lhe interessavam.

Porém, nada disso era tão atraente quanto o espetáculo vislumbrado à direita: uma escrivaninha diminuta, uma underwood de museu, cujos restos mortais envergonhavam a velhice sob pilhas de processos. Mas qualquer deslumbramento se ofuscava no responsável por todo aquele conjunto de velharias. Evidentemente, tratava-se de um rei. (GIUDICE, 1985: 21)

O primeiro elemento é uma máquina de escrever, que não é qualquer máquina, mas uma "underwood de museu", da qual o narrador destaca o péssimo estado de conservação. Sua caracterização como peça de museu não lhe concede status de relíquia ou de objeto de arte $^{3}$; ao contrário, aponta uma valoração depreciativa, em que o museu é tomado como lugar de "velharias". A underwood deteriorada, destacada entre as outras máquinas de escrever pela especificação de sua marca, remete ao passado, ou melhor, ao ultrapassado, consistindo em símbolo de decadência e complemento da caracterização que se faz do personagem apresentado como "rei".

O rei-interrogador, vestindo paramentos monárquicos e uma gravata marrom (daquelas de laço pronto), é logo denominado jocosamente pelo narrador como "reizinho-datilógrafo": centro do poder

3 Underwood é uma das mais tradicionais marcas de máquinas de escrever. $\mathrm{O}$ primeiro modelo surgiu no final do século XIX. O modelo Underwood 5 , surgido em 1901, tornou-se um dos mais populares entre todas as máquinas de escrever, tendo sido fabricadas milhões de unidades durante cerca de trinta anos de produção. Por isso mesmo, o modelo ainda não se tornou uma raridade e pode ser encontrado com relativa facilidade por colecionadores. É justamente o seu sucesso comercial, aliado ao design diferenciado, que dota esse modelo de uma importância histórica que impõe sua inclusão em qualquer "museu de máquinas de escrever". Um fato interessante é que, na própria época de sua fabricação, a Underwood 5 acabou (de certo modo) virando peça de museu. Em 1916, Marcel Duchamp expôs um ready-made que consistia numa capa de máquina de escrever Underwood. 
Scoville, André. O fantasma do autoritarismo nas narrativas de Victor Giudice

e de suas atenções naquele espaço "tríplice", referido ora como escritório, ora como museu, e ainda assim (não se pode esquecer) parte da prisão.

Um dos alvos preferidos por Giudice ao qual dirige sua crítica muitas vezes abertamente satírica é a postura autoritária de quem detém certo poder. Essa postura é apontada em diversas esferas da sociedade, como na doméstica e familiar, do trabalho e da política. Dos diferentes "reis" dessas diferentes esferas, Giudice expõe a pequenez. São apenas reizinhos que uma vez que perdem o poder revelam sua "real mediocridade".

Acompanhando todos os movimentos dessa longa passagem da ditadura à democracia, Giudice faz ver como o que se superou em 1985 não foi o autoritarismo, mas apenas sua forma oficial, institucional e mais evidente. Nesse jogo de espelhos entre o governo e a sociedade, não se pode dizer que o comportamento autoritário tenha sido inventado pela ditadura, no entanto, incentivado por ela, infiltra-se com mais força na sociedade que a reproduz em suas relações. Ao mesmo tempo, essa violência também emana das próprias relações sociais permitindo que esse fantasma do autoritarismo continue a nos assombrar nos momentos de crise politica.

Nesse sentido, é também contra esse autoritarismo incutido na sociedade que Giudice dirige sua crítica. Basta lembrar o destino do personagem protagonista de "A válvula", de Necrológio, em que um chefe prepotente, Franciseh, após a aposentadoria, dá à luz um reizinho (tomando ao pé da letra a expressão "ter um rei na barriga") e então vai encolhendo até tornar-se um inseto e ser mandado descarga abaixo pela própria esposa, A epígrafe desse conto ("- Agora, não posso. Vou almoçar. Se quiser, sente e espere." - GIUDICE, 1972: 37) não vem com indicação de autoria, apesar de se poder pensar em algum antigo chefe de Giudice. Mas é melhor assim, sem autor. Afinal, pode-se dizer que os autores são vârios e estão espalhados por toda a parte. Podem ser encontrados nas delegacias, 
Rev. ANPOLL, $\mathrm{n}^{\circ}$ 21, p. 11-27, jul./dez. 2006.

nos tribunais, nas repartições públicas, nas empresas privadas, nas escolas, nos hospitais, nos hotéis, nos restaurantes, nas universidades, nas igrejas, nas fábricas, nos quartéis, nas prisões e dentro de nossas casas.

\begin{abstract}
Covering the literary trajectory of the writer Victor Giudice, a recurrent concern with the question of the authoritarianism is noticed in his narratives. The publication of his works coincides with some key-moments of Brazilian political history. Using a metaphorical language, Giudice approaches the political changes occurred in the period that goes from the height of the institutionalized violence by the military dictatorship until the consolidation of the democratic system. His narratives also lead to a reflection on the authoritarianism as a present element in the social relations.
\end{abstract}

KEY WORDS: Victor Giudice; Brazilian contemporary literature; politics; authoritarianism; military dictatorship.

\title{
BIBLIOGRAFIA
}

Giudice, V. (1972). Necrológio. Rio de Janeiro: O Cruzeiro. - (1985). Bolero. Rio de Janeiro: Rocco. - (1999). O Museu Darbot e outros mistérios \& Do catálogo de flores. Rio de Janeiro: José Olympio.

Foucault, M. (1977). Vigiar e punir. Nascimento da prisão. Trad. Lígia M. Pondé Vassallo. Petrópolis: Vozes. 